\title{
Conjunctival Melanoma
}

National Cancer Institute

\section{Source}

National Cancer Institute. Conjunctival Melanoma. NCI Thesaurus. Code C4550.

A malignant melanoma within the conjunctiva of the eye. 